\title{
Can HMG Co-A reductase inhibitors ("statins") slow the progression of age-related macular degeneration? The Age-Related Maculopathy Statin Study (ARMSS)
}

\author{
Robyn H Guymer ${ }^{1,3}$ \\ Peter N Dimitrov' \\ Mary Varsamidis' \\ Lyndell L Lim ${ }^{1,3}$ \\ Paul N Baird' \\ Algis J Vingrys ${ }^{2}$ \\ Luba Robman ${ }^{1,3}$
}

'Centre for Eye Research Australia, University of Melbourne, Melbourne, Victoria, Australia; ${ }^{2}$ Department of Optometry and Visual Sciences, University of Melbourne, Melbourne, Victoria, Australia; ${ }^{3}$ Royal Victorian Eye and EAR Hospital, Melbourne, Australia

Correspondence: Luba Robman

Centre for Eye Research Australia, 32

Gisborne Street, East Melbourne,VIC

3002, Australia

Tel +61399298360

Fax +6I 396625938

Email liubov@unimelb.edu.au

\begin{abstract}
Age-related macular degeneration (AMD) is responsible for the majority of visual impairment in the Western world. The role of cholesterol-lowering medications, HMG Co-A reductase inhibitors or statins, in reducing the risk of AMD or of delaying its progression has not been fully investigated. A 3-year prospective randomized controlled trial of $40 \mathrm{mg}$ simvastatin per day compared to placebo in subjects at high risk of AMD progression is described. This paper outlines the primary aims of the Age-Related Maculopathy Statin Study (ARMSS), and the methodology involved. Standardized clinical grading of macular photographs and comparison of serial macular digital photographs, using the International grading scheme, form the basis for assessment of primary study outcomes. In addition, macular function is assessed at each visit with detailed psychophysical measurements of rod and cone function. Information collected in this study will assist in the assessment of the potential value of HMG Co-A reductase inhibitors (statins) in reducing the risk of AMD progression.
\end{abstract}

Keywords: age-related macular degeneration, progression, randomized controlled trial, HMG Co-A reductase inhibitor, statin, visual function

\section{Introduction}

Age related macular degeneration (AMD), a progressive late onset disease affecting central vision, is the leading cause of irreversible blindness in western countries (Mitchell et al 1995; VanNewkirk et al 2000; Smith et al 2001). AMD prevalence increases exponentially with age, and with the increase in life expectancy, the burden of this disease will increase over the coming decades (VanNewkirk et al 2000; Taylor 2002). Current treatment options for AMD are largely aimed at limiting the impact of the late neovascular complications of AMD. Currently only the AREDS supplementation has been shown to have some benefit in reducing the risk of vision loss in some groups of high risk early AMD (Sackett and Schenning 2002). Further options are needed to slow the development of vision loss, and ultimately to prevent the disease from occurring.

HMG Co-A reductase inhibitors have pleotrophic actions, far wider than just their cholesterol-lowering properties for which they are mostly prescribed. Many of these actions may be beneficial in reducing the risk of AMD. In addition to benefits achieved by reducing serum lipid levels (Hunninghake et al 1990; Bellosta et al 2000; Takemoto and Liao 2001; Watts 2001), the nonlipid-related effects of these drugs may be even more important in AMD pathogenesis (Guymer et al 1999; Pruefer et al 1999; Spaide et al 1999; Bellosta et al 2000; Inoue et al 2000; Alvarez de Sotomayor and Andriantsitohaina 2001; Hageman et al 2001; Haimovici et al 2001; Hess and 
Fagan 2001; Jialal et al 2001; Kwak et al 2001; Takemoto and Liao 2001; Kuvin and Karas 2003; Friedman 2004). The recent genetic and pathological findings implicating the complement pathway and inflammation in the etiology of AMD (Edwards et al 2005; Hageman et al 2005; Haines et al 2005; Klein et al 2005) suggest that the anti-inflammatory actions of statins may also be valuable in AMD.

The association between AMD and the use of cholesterollowering medications has been examined by a number of clinical studies, and there is a growing body of evidence that such an association exists, and it is inverse. The first study to investigate a possible protective effect was a cross-sectional population-based study which found subjects who took statins had a one eleventh risk of having AMD compared to those who did not (Hall et al 2001). The Melbourne Visual Impairment Project (VIP) showed that, whilst there was a positive association with the actual prevalence of AMD and cholesterol-lowering medication (perhaps explained by a possible association between cardiovascular disease and AMD), participants on these medications were almost four times less likely to experience progression than those not taking medication (3.6\% vs 13\%), although this difference was not significant (McCarty et al 2001a, 2001b).

In a large, nested case-control study, involving 550 cases and 5500 matched controls (McGwin et al 2003), cases of early AMD were $50 \%$ less likely to have filled a statin prescription compared to those without early AMD, possibly supporting the protective effect of statins in the development of AMD.

A retrospective case series found that therapy with statins was associated with an almost 50\% reduction in the risk of developing choroidal neovascularization (CNV) (Wilson et al 2004). An inverse association was also reported in a case-control study, based on the Atherosclerosis Risk in Communities cohort study, where use of cholesterol-lowering medications was inversely associated with AMD (McGwin et al 2005).

However, not all studies find a protective effect, with a population-based case-control study, based on the UK General Practice Research Database, not finding a protective effect of statins (Smeeth et al 2005). The large populationbased Beaver Dam Eye Study, (BDES) and Rotterdam Eye Study (RES) found no protective effect of lipid-lowering medications on the 5-year incidence or progression of early AMD, despite the detected association of elevated HDL cholesterol and AMD in RES (Klein et al 2003b; van Leeuwen et al 2004b). Though, only 3.9\% of the BDES took statins at baseline (Klein et al 2003a). These analyses also included all lipid-lowering agents, not just statins. Similarly, Delcourt and colleagues (2001) reported an absence of association between lipid-lowering medications and late AMD in a cross sectional population-based study.

The limitation of such population-based studies is their reliance on subject recall with regard to medications taken. Statins have only relatively recently become a common medication amongst people over 50 years. As a result, many of these studies were underpowered in evaluating the effect of just statins, with a possibility of its effect being confounded by the inclusion of a diverse group of lipidlowering drugs. Also, perhaps the effect of statins requires a long follow up time to detect, especially when used in people already with significant disease. Thus, 10-years of observation in the BMES showed statin to be protective for indistinct soft drusen, a key late AMD precursor lesion (Tan et al 2007). This finding did in fact reverse the previous negative findings from the 5-year BMES follow up (van Leeuwen et al 2004b).

The role of statins in AMD is clearly topical and the current evidence is contradictory (see also Table 5). It has been addressed in a meta-analysis of eight studies where a relative risk of 0.74 was observed between users of lipidlowering medications in comparison to nonusers (95\% CI 0.55-1.00) (Chuo et al 2007). These pooled studies were very heterogeneous (Ri 0.85, p < 0.001) and it was concluded that it was difficult to determine the relationship between lipid-lowering medications and the risk of developing AMD with the existing literature, thereby highlighting the need for a prospective randomized controlled trial.

Although some have argued that a RCT would be difficult to conduct due to the large sample size required, difficulties in having a placebo group and possible side effects of statins in subjects with normal cholesterol (Klein and Klein 2004; Baker and Tarnopolsky 2005; Lamperti et al 2005), a growing body of evidence and conflicting results from the observational and case-control studies, along with a biologically plausible protective effect of statins, justifies a need for a randomized controlled trial to definitively address the question of the potential use of statins in AMD. To date, no randomized controlled trial on statins in AMD has published any findings.

Here we describe the design of a randomized controlled trial entitled Age-Related Maculopathy Statin Study (ARMSS), which aims to determine whether the use of HMG $\mathrm{Co}-\mathrm{A}$ reductase inhibitor simvastatin is effective in preventing the progression of early AMD to the vision threatening complications of this disease. 


\section{Materials and methods}

\section{Study design}

ARMSS is a 3-year randomized, placebo-controlled, double-masked trial of simvastatin, $40 \mathrm{mg}$, versus placebo in a population of AMD-affected volunteers in Melbourne, Australia. The project has been approved by the Research and Ethics Committee of the Royal Victorian Eye and Ear Hospital, undertaken according to the Helsinki Declaration for the research on humans and registered with the Australian Clinical Trial Registry. Written informed consent was obtained from all participants prior to entry to the study.

\section{Objectives}

The primary objective of this study is to determine the effect of simvastatin (40 mg daily) in preventing or slowing the progression of age-related macular degeneration over a 3-year period, based on the grading of fundus photographs.

Secondary objectives of this study are:

a) To assess the effect of simvastatin on macular visual function in early AMD.

b) To explore the effect of genetic variability on the outcome in this cohort.

\section{Recruitment}

Participants were recruited from a previous study on AMD where participants were enrolled in the 1990's with early AMD to identify risk factors for progression. After the end of that study participants were invited to enrol in the new study (Robman et al 2004). They were also enrolled from medical retinal clinics at the Royal Victorian Eye and Ear Hospital, Melbourne, Australia, and from private medical retinal specialists in Melbourne. Clinicians involved in the study approached patients with eligible ocular findings and if interested the person was asked to attend the study clinics.

\section{Eligibility criteria}

Eligibility criteria (Table 1) were as follows: 1) age $>$ 50 years; 2) absence of bilateral end stage AMD, glaucoma, diabetes, significant cataract (cortical cataract $\geq 4 / 16$ pupil diameter, posterior subcapsular cataract $\geq 1 \mathrm{~mm}^{2}$, nuclear cataract $\geq$ Grade 2.0 based on the Wilmer system for lens opacity grading) (Taylor and West 1988), and any other ocular, neurological, or systemic disease that may compromise vision; 3) not using medications that may affect the retina (Ludvigh and McCarthy 1938; Said and Weale 1959; Gunkel and Gouras 1963); 4) lipid profile not consistent with the National Heart Foundaton of Australia and the Cardiac Society of Australia and New Zealand guidelines for treatment with a lipid-lowering agent (see below and Table 1); 5) absence of conditions for which statins are clinically contraindicated; 6) no allergies or history of severe adverse reactions to statins; 7) alanine aminotransferase (ALT) level not over 2 times the normal range.

AMD eligible criteria were: 1) high-risk feature of early AMD in both eyes; 2$)>1$ large soft druse $(>125 \mu \mathrm{m})$ or extensive intermediate drusen (63-124 $\mu \mathrm{m})$ in both eyes; 3 ) one eye with late AMD and the other with pigment changes or soft drusen of any size. In the Macular Photocoagulation study (MPS) (MPSG 1991), a visual acuity of 20/60 or better in at least one eye was required.

To be included in this study, the fasting lipid profile was not allowed to meet the National Heart Foundation of

Table I Inclusion and exclusion criteria

\begin{tabular}{|c|c|}
\hline Inclusion criteria & Exclusion criteria \\
\hline Male or female aged 50 years or older & Bilateral end stage AMD (CNV, central GA) \\
\hline VA better than or equal to $20 / 60$ in one eye. & Macula cannot be assessed in at least one eye \\
\hline High risk drusen in both eyes: $\geq 1$ large soft druse $(\geq 125$ & Medical and ophthalmic conditions which potentially affect visual function - \\
\hline microns), or $>10$ intermediate drusen ( $\geq 63$ microns and & including visually significant cataract (defined by Wilmer grading method \\
\hline$<125$ microns) OR & as nuclear opacity grade 2 or greater, cortical opacity greater than grade 2 , \\
\hline $\begin{array}{l}\text { Late AMD (CNV, central GA) in one eye and any drusen or } \\
\text { pigment change in the study eye }\end{array}$ & posterior subcapsular cataract $\left.\geq 1 \mathrm{~mm}^{2}\right)$, history of diabetes and glaucoma \\
\hline Cholesterol level within normal limits according to PBS & Use of medications that may affect visual function, such \\
\hline \multirow[t]{5}{*}{ criteria (Table 2) } & as plaquenil, chloroquine, major tranquilizers. \\
\hline & Currently on cholesterol-lowering medication. \\
\hline & Use of statins is contraindicated \\
\hline & Alanine aminotransferase (ALT) $>2$ times the upper limit of normal \\
\hline & Previous severe adverse or allergic reactions to statins \\
\hline
\end{tabular}

Abbreviations: AMD, age-related macular degeneration; CNV, choroidal neovascularization; GA, geographic atrophy; PBS, pharmaceutical benefits schedule; VA, visual acuity 
Australia and the Cardiac Society of Australia and New Zealand guidelines for treatment with a lipid-lowering agent (Jones et al 1998; NHFA 2001) (Table 2). In a placebocontrolled randomized trial, it was considered unethical to include individuals whose cholesterol levels required treatment. Thus, to be eligible, all recruits had to return "normal" cholesterol levels. If during the course of the trial a recruit needed to start treatment, their physician was asked to use simvastatin. The participant continued in an "off protocol" fashion in the study. Many potential recruits became ineligible, either because they were already taking statins or their pre-enrolment cholesterol test results were such that they were referred to their physician for consideration of commencing cholesterol-lowering medication. A full listing of inclusion and exclusion criteria is outlined in Table 1.

\section{Screening}

Subjects who were referred to the study team were contacted by trained research staff and asked to provide a fasting lipid level, either from their general practitioner or through a request sent out to them from the study team. If lipid levels were elevated, the participants were not recruited but notified and referred to their local doctors. Participants with lipid profiles that allowed entry into the study were invited along to the screening and baseline examination.

Table 2 Pharmaceutical Benefits Schedule (PBS) qualifying criteria for subsidized statin prescriptions in Australia*

\begin{tabular}{|c|c|}
\hline Patient conditions & $\begin{array}{l}\text { Lipid level for PBS } \\
\text { subsidy }\end{array}$ \\
\hline Existing coronary heart disease & Cholesterol $>4.0 \mathrm{mmol} / \mathrm{L}$ \\
\hline Diabetes mellitus & Cholesterol $>6.5 \mathrm{mmol} / \mathrm{L}$ \\
\hline Familial hypercholesterolemia & or \\
\hline $\begin{array}{l}\text { Family history of coronary heart } \\
\text { disease (Ist degree relative }<60 \\
\text { yrs of age) }\end{array}$ & $\begin{array}{l}\text { Cholesterol }>5.5 \mathrm{mmol} / \mathrm{L} \\
\text { and } \mathrm{HDL}<1.0 \mathrm{mmol} / \mathrm{L}\end{array}$ \\
\hline \multicolumn{2}{|l|}{ Hypertension } \\
\hline \multicolumn{2}{|l|}{ Peripheral vascular disease } \\
\hline $\mathrm{HDL}$ Cholesterol $<1.0 \mathrm{mmol} / \mathrm{L}$ & Cholesterol $>6.5 \mathrm{mmol} / \mathrm{L}$ \\
\hline $\begin{array}{l}\text { Men } 35-75 \text { yrs of age } \\
\text { Postmenopausal women } \\
\text { up to } 75 \text { yrs of age } \\
\end{array}$ & $\begin{array}{l}\text { Cholesterol }>7.5 \mathrm{mmol} / \mathrm{L} \\
\text { or Triglycerides }>4.0 \mathrm{mmol} / \mathrm{L}\end{array}$ \\
\hline If not eligible under the above & $\begin{array}{l}\text { Cholesterol }>9.0 \mathrm{mmol} / \mathrm{L} \text { or } \\
\text { Triglycerides }>8.0 \mathrm{mmol} / \mathrm{L}\end{array}$ \\
\hline
\end{tabular}

Note: Adapted from the November 2002 Schedule of Pharmaceutical Benefits. Abbreviations: HDL, high-density lipoprotein.
Having provided written informed consent, visual acuity and fundus examination was carried out via the baseline protocol outlined below to determine eligibility based on the ophthalmic assessment. Once this eligibility was confirmed, all remaining baseline examinations were performed (see Table 3).

\section{Protocol}

Baseline examination consisted of questionnaires, ophthalmic examination, blood draw, and visual function testing. The questionnaires (Table 3 ) gathered data on baseline demographics, general medical and family history, and risk factors for eye disease, including dietary intake, pharmaceutical intake, and specific medical conditions. In addition, ethnic origin and family history of AMD, functional questionnaire (Impact of Visual Impairment [IVI] Questionnaire) (Keeffe et al 1999; Hassell et al 2000), and cognitive function questionnaires were administered.

Ophthalmic examination included visual acuity, refractometry, ocular tonometry, fundus photography, and slit lamp examination. Best corrected visual acuity was measured at each time-point using a rear-illuminated Log MAR visual acuity chart at 4 metres and at 1 metre when required (Bailey and Lovie 1976). Failing this, recognition of hand movements or light perception was attempted.

Ophthalmic examination was performed with a standard slit lamp. All study participants were examined by a qualified ophthalmologist, and, where clinically indicated, fluorescein angiography was undertaken to exclude CNV. A prior history of complications of late AMD was noted and confirmed by examination.

Nonstereoscopic $45^{\circ}$ macular images were taken with dilated pupils using a digital Canon CR6-45NM NonMydriatic Retinal Camera (Saitama, Japan). Images were viewed immediately and repeated if unsatisfactory. Fundus grading of each image was conducted at a later stage by two trained graders using the "OptoMize PRO" software from Digital Healthcare Image Management System (Digital Healthcare Ltd [DH], Cambridge, UK) on a high resolution computer screen. Grading of macular characteristics was carried out according to the International Classification and Grading System for AMD (Bird et al 1995). Each macula was graded for the absence or presence, size, location, number, centrality, and area covered by the following features: hard, intermediate, distinct and indistinct drusen, retinal pigment epithelium changes, geographic atrophy, and neovascular changes. Presence of other pathology was also recorded. 
Table 3 Schedule for procedures involved in the Age-related maculopathy statin study

\begin{tabular}{|c|c|c|c|c|c|c|c|c|c|}
\hline \multirow[t]{2}{*}{ Procedures } & \multirow[t]{2}{*}{ Screening visit } & \multirow{2}{*}{$\begin{array}{l}\text { Baseline } \\
\text { examination }\end{array}$} & \multicolumn{7}{|c|}{ Follow-up time in months } \\
\hline & & & $\mathrm{I}$ & 6 & 12 & 18 & 24 & 30 & 36 \\
\hline Study explanation & $\checkmark$ & $\checkmark$ & & & & & & & \\
\hline Consent & & $\checkmark$ & & & & & & & \\
\hline Randomization & & $\checkmark$ & & & & & & & \\
\hline $\begin{array}{l}\text { Blood draw for cholesterol and liver } \\
\text { function tests }\end{array}$ & $\checkmark$ & & & $\checkmark$ & $\checkmark$ & $\checkmark$ & $\checkmark$ & $\checkmark$ & $\checkmark$ \\
\hline Blood draw for DNA tests & & $\checkmark$ & & & & & & & \\
\hline Medical history & $\checkmark$ & $\checkmark$ & & $\checkmark$ & $\checkmark$ & $\checkmark$ & $\checkmark$ & $\checkmark$ & $\checkmark$ \\
\hline Listing of medications & $\checkmark$ & $\checkmark$ & & $\checkmark$ & $\checkmark$ & $\checkmark$ & $\checkmark$ & $\checkmark$ & $\checkmark$ \\
\hline Mini-mental questionnaire & & $\checkmark$ & & & & & & & \\
\hline Impact of Visual Impairment (IVI) survey & & $\checkmark$ & & & & & & & $\checkmark$ \\
\hline Refraction & & $\checkmark$ & & $\checkmark$ & $\checkmark$ & $\checkmark$ & $\checkmark$ & $\checkmark$ & $\checkmark$ \\
\hline Visual acuity & $\checkmark$ & $\checkmark$ & & $\checkmark$ & $\checkmark$ & $\checkmark$ & $\checkmark$ & $\checkmark$ & $\checkmark$ \\
\hline Pupil dilation & $\checkmark$ & $\checkmark$ & & $\checkmark$ & $\checkmark$ & $\checkmark$ & $\checkmark$ & $\checkmark$ & $\checkmark$ \\
\hline Slit lamp examination & $\checkmark$ & $\checkmark$ & & $\checkmark$ & $\checkmark$ & $\checkmark$ & $\checkmark$ & $\checkmark$ & $\checkmark$ \\
\hline Macular photography & & $\checkmark$ & & $\checkmark$ & $\checkmark$ & $\checkmark$ & $\checkmark$ & $\checkmark$ & $\checkmark$ \\
\hline Visual function tests & & $\checkmark$ & & $\checkmark$ & $\checkmark$ & $\checkmark$ & $\checkmark$ & $\checkmark$ & $\checkmark$ \\
\hline Reporting of side effects & & & $\checkmark$ & $\checkmark$ & $\checkmark$ & $\checkmark$ & $\checkmark$ & $\checkmark$ & $\checkmark$ \\
\hline Food Frequency Questionnaire & & $\checkmark$ & & & & & & & \\
\hline
\end{tabular}

Where disagreement occured between the two graders, the results were adjudicated by a retinal specialist ( $R G)$.

Periodical evaluation of grading was undertaken to assess intra- and inter-grader reproducibility. An unweighted kappa statistic with $95 \%$ confidence interval was used as a measure of reliability.

\section{Visual function testing}

Visual function was monitored at each time-point of the study (every 6 months) in one eye only. Thus the study eye for these tests was the eye with visual acuity of $20 / 60$ or greater. If both eyes meet all the other inclusion criteria as well as visual acuity, the eye with the more advanced stage of disease (according to the fundus appearance) was chosen as the study eye for visual function testing. All other assessments were carried out in both eyes. Patients with glaucoma, diabetes, significant cataract and retinotoxic drugs were excluded because they could interfere with the interpretation of the functional tests.

Psychophysical measurements included colors perception thresholds (red and blue), spatiotemporal contrast sensitivity thresholds (4 and $14 \mathrm{~Hz}$ flicker), central visual field testing (thresholds for static and flickering targets up to $10^{\circ}$ eccentricity), dynamics of glare recovery (time constant and absolute threshold) and dark adaptation (time constant and absolute thresholds for both cone and rod components, as well as the rod-cone break).
Details of the testing procedure and technical characteristics have been described elsewhere (Phipps et al 2003; Dimitrov et al 2008). Testing was conducted using specially developed software hosted in a G4 Macintosh (Apple, Cupertino, CA, USA) computer. Stimuli were presented on a calibrated and gamma-corrected (Metha et al 1993; Zele and Vingrys 2005) high-resolution CRT monitor (Hitachi Accuvue HM-4721-D; Hitachi; Tokyo; Japan) powered by an 8-bit NVIDIA video-card. The examination was controlled via a second monitor (examiner's display). Color and flicker thresholds and glare recovery were measured using a central (foveal) stimulus, $2^{\circ}$ in size. The same target size was used for all cone tests to provide a direct functional comparison over a common retinal region. Dark adaptation dynamics were tested either with a foveal $4^{\circ}$ stimulus or with $2^{\circ}$ spots located at $4^{\circ}$ and at $10^{\circ}$ in inferior field. The $4^{\circ}$ and $10^{\circ}$ degree locations were chosen to compare vulnerable retinal regions (Curcio et al 1996; Owsley et al 2000).

All visual function tests were conducted monocularly following pupil dilation. Prior to any testing, participants were adapted to ambient light levels ( $\geq 30$ candela per $\mathrm{m}^{2}$ ) for at least 15 minutes. Subjects' refractive correction for the test distance was worn over the study eye and the fellow eye was patched. A chin rest with forehead restraint was used to stabilize viewing distance. Psychophysical testing was 
preceded by a familiarisation and training period ( $\leq 2 \mathrm{~min}$ ) at each visit.

Automated perimetry of the macular $10^{\circ}$ field was undertaken with static and flickering achromatic stimuli for the study eye of each participant using a Medmont M700 perimeter (Medmont Pty Ltd, Camberwell, Victoria, Australia) to identify focal areas of markedly decreased sensitivity so that these areas could be avoided in all subsequent testing. Flicker thresholds were measured at two temporal frequencies, 4 and $14 \mathrm{~Hz}$. Color thresholds were measured for isoluminant red and blue increments. Flickering and colored spots were presented for 1 second including a 200-ms ON and OFF cosine ramp. The subject's task was to fixate foveally the center of the display monitor indicated by two vertical and two horizontal rectangular markers $\left(0.5^{\circ} \times 4^{\circ}\right.$ in size $)$ and to respond to the presence of a stimulus, whose potential presence was signalled by an auditory tone. False positive and false negative trials were injected randomly into the test procedure at a $25 \%$ rate. Subjects were instructed to minimize the occurrence of false responses and any test that yielded $\geq 10 \%$ false responses was repeated.

Cone recovery was tracked after exposure of the study eye to an intense light ( $>95 \%$ photopigment bleach). Prior to exposure, a criterion threshold was established with recovery time being measured for five multiples of criterion threshold.

For cone and rod dark adaptation, the following parameters were measured: cone recovery rate (decades per min) and absolute threshold $\left(\log \mathrm{cd} / \mathrm{m}^{2}\right)$, rod -cone transition time (rod-cone break; RCB; $\mathrm{min}$ ) and rod-second-phase recovery rate (decades per min). These clinically important components (Lamb 1981; Lamb and Pugh 2004; Dimitrov et al 2008) were isolated by judicious selection of stimulus size, stimulus location, level of the pigment bleach, luminance output of the display monitor and test duration $(30 \mathrm{~min})$. The full test procedure, technical characteristics and modelling of the dynamics of the cone and rod recovery have been described elsewhere (Brown et al 1986; Owsley et al 2001; Phipps et al 2003; Dimitrov et al 2008).

In our preliminary studies, visual function tests showed high sensitivity and specificity for AMD, eg, 93\% of the AMD participants had at least one recovery parameter that was abnormal. The diagnostic capacity was high, eg, area under the curve in the receiver operator characteristic was $0.98 \pm 0.01$ for cone recovery and $0.92 \pm 0.04$ for rod recovery. The variability of the indices determined by our technique by retesting a subset of controls $(\mathrm{n}=16)$ and patients $(n=24)$ after $16 \pm 6.5($ mean $\pm S D)$ days show for rod-cone break a coefficient of variation $32 \%$ (controls) and $44 \%$ (AMD). This is similar to the variability found with clinical perimetry (Demirel and Vingrys 1994) indicating that our method has potential as a clinical application for the early detection of persons with AMD (Dimitrov et al 2008).

\section{Blood tests}

Fasting blood samples are taken at each visit to measure; fasting lipid profile, including total cholesterol level, high- and low-density lipoprotein cholesterol, triglyceride level, liver function test (to monitor for drug toxicity), and high sensitivity C-reactive protein, a measure of systemic inflammation, is also taken at screening, 12 months, and 3 years. Participants are notified and advice given to seek appropriate action if the results are abnormal. If the cholesterol levels rise once in the study, we request that the general practitioner uses simvastatin $40 \mathrm{mg}$ if possible. If so, the participant stays in the study off protocol.

At baseline, blood samples were also taken for DNA analysis. DNA will be extracted and analysed for variants of AMD-related genes using the MassEXTEND reaction of the Sequenom platform. This will allow stratification of AMD progression rates by genotypes, which has been important in our other progression cohort (Baird et al 2006, 2008).

\section{Intervention}

The intervention under assessment in this trial is simvastatin as a single $40 \mathrm{mg} /$ day dose. Both simvastatin and the placebo medication were supplied by Merck Sharp and Dohme (Sydney, Australia) in tablet form. The placebo tablets are indistinguishable by sight or taste from the active medication. The pharmacy department at the Royal Victorian Eye and Ear Hospital (RVEEH) packages the medication into numbered bottles allocated to two groups, A and B. A randomization schedule was prepared by a biostatistician using a permuted blocks allocation scheme. The participants received numbered bottles of either placebo or simvastatin tablets, randomized in a ratio of 1:1. The medication codes are stored in a secure location and are not accessible by study personnel involved in the examination of participants and the analysis of results.

\section{Follow-up protocol}

The study drug, at $40 \mathrm{mg}$ daily, or placebo, was given over a 3 -year study period, with follow-up examination performed at 6-month intervals throughout the three years, according to the list of procedures in Table 3. 


\section{Adverse events}

Hepatotoxicity and rhabdomyolysis are serious side effects of statins (Alcocer 2003). Liver function tests were performed routinely to ensure no liver toxicity. If the participants complained of unexplained muscle pain they were discontinued from the treatment. An independent safety committee reviews the adverse event rates in the placebo and active medication groups.

\section{Study analysis}

The primary objective of this randomized controlled trial is progression of AMD, either to the development of late stage $\mathrm{AMD}$, defined as either $\mathrm{CNV}$ or central geographic atrophy or as progression through stages of early AMD. Secondary objectives are to measure changes in visual function results over time and to determine how the genotype influences progression.

\section{Progression to late AMD}

Appearance of the late complications of AMD, both central geographic atrophy (GA) and CNV, was adopted as the end point for an eye. Any symptoms or signs of CNV is immediately referred to a medical retina specialist (RG) and managed appropriately according to available standard treatments for $\mathrm{CNV}$. If late $\mathrm{AMD}$ occurs in the one eye of two eligible eyes, the participants will continue to receive medication, and the course of the disease in the fellow eye will be observed. If both eyes reach late stage disease, the study treatment will be ceased and the subject will be exited from the study.

\section{Progression of early AMD}

Although the main study outcome is progression from early to late AMD, progression or reversal of early AMD features are also assessed. AMD status in each eye at baseline and at each follow-up visit is stratified according to a 6-level severity scale as follows: Level 1 - no drusen/hard drusen only; Level 2 - intermediate drusen OR hyperpigmentation without hypopigmentation; Level 3 - soft distinct or indistinct drusen OR hypopigmentation (with or without hyperpigmentation); Level 4 - soft distinct or indistinct drusen AND pigmentary abnormalities (hyper- or hypopigmentation); Level 5 - geographic atrophy; Level 6 - neovascular AMD (Taylor et al 2002; Tikellis et al 2007).

Progression is defined as either an increase by one or more levels in either eye from level 2, 3, or 4 at baseline to the follow up time point, or cases that showed an increase of 2 or more steps in the specific grades of drusen or pigmentary changes as defined by the International classification for AMD grading. For drusen, such grades involve a change in morphology, number, drusen type, location, size and area covered, whereas for pigmentary changes differences in size and location are assessed. We assumed a greater clinical severity and a higher risk of developing late AMD with each successive level, based on previous findings (Tikellis et al 2007). Regression of early AMD features may imply either a decrease in risk of progression to the late stage, or a replacement of these features by more severe signs of late AMD. All cases are to be verified by an independent sideby-side comparison of baseline and follow-up photos.

\section{Progression based upon visual function}

The results of the visual function examinations will be analyzed for each test separately. Both ways will be employed to ensure the robustness of findings:

(1) comparison of visual function in two treatment groups on a continuous scale, and

(2) event analysis, where we define a case as progressed if a measurement in visual function test is outside of a $95 \%$ confidence interval of the original distribution for this test on two consecutive biannual examinations.

These tests may provide additional information on disease severity and progression (Sunness et al 1989; AREDS 1999; Sackett and Schenning 2002). Rod and cone sensitivity may provide another method of assessing the effect of statins over a shorter time, long before a change in macular grading of AMD characteristics can be detected (Owsley et al 2000; Phipps et al 2003). Any test that could detect benefit of an intervention more efficiently than macula grading would offer great potential when studying other interventions in the future.

\section{Genotype analysis}

Haplotype analysis will be applied to genetic information collected in this study (Hageman et al 2005). A haplotype is a series of consecutive alleles on a particular chromosome. Haplotypes are broken down every generation However, recombination occurs preferentially in specific regions, known as haplotype blocks. Because alleles are correlated with each other in a haplotype block, knowing these structures in a population allows us to optimize the amount of the genetic information without having to genotype all potential single nucleotide polymorphisms (SNPs). 
From our preliminary work we have established that we will need 4 tSNPs for the $C F H$ gene, 2 tSNPs for the APOE gene, 22 tSNPs for the CFHR1-5 genes, 7 tSNPs for the $B 2 / C F$ genes, and 25 tSNPs for the PLEKHA1/ LOC387715/HTRA1 gene cluster. Thus we will use a total of 60 SNPs across the regions of interest. Genotyping will be performed using the MassARRAY ${ }^{\circledR}$ platform (SEQUENOM) through the Australian Genome Research Facility (AGRF) in Brisbane, Australia. We have already undertaken use of this procedure in our preliminary study of the risk associated with the $\mathrm{Y} 402 \mathrm{H}$ variant of the $\mathrm{CFH}$ gene.

\section{Sample size}

The sample size calculation was based on AMD change measured (1) traditionally, by visual/photographic detection, and (2) by detection of significant changes in visual sensitivity and the time of rod-cone break in dark adaptation.

The photo-based detection rate of visible progression of high risk early AMD in the AREDS and CHARM Studies was about 5\% per year (AREDS 2001; Tikellis et al 2007). In the Melbourne VIP, the number of people whose AMD progressed was 4 times lower in those on cholesterol-lowering medications than in those not on any such medication (McCarty et al 2001b). To detect a similar reduction in AMD progression, a sample size of 118 subjects in each arm, followed for three years, was needed to reach $80 \%$ power at a $5 \%$ level of significance.

We hypothesized, however, that we should detect changes in function earlier than clinical changes and thus have an answer regarding the use of statins at an earlier time than if we followed up participants purely on clinical criteria. Therefore, when calculating the sample size using functional outcomes, a smaller sample size would be required and yield greater experimental power.

For the power and sample size calculation based on visual function tests, we established repeatability of these tests and variability of visual function measurements in the sub-sets of the participants.

To determine repeatability of various measurements (thresholds for 4 and $14 \mathrm{~Hz}$ flicker and red and blue colors, as well as rod-cone break in dark adaptation) the same examiner conducted repeated measurements on 26 participants with 2 to 6 weeks interval.). Intra-class correlation coefficients for these measurements were 0.74 for red, 0.84 for blue, and 0.89 for both flicker thresholds. It was 0.87 for the rod-cone break in dark adaptation.

Variability of these assays was measured in a sample of 35 patients with early AMD. The coefficient of variation
(CV), which reflected inter-participant performance, was used in our power analysis. Among the visual function tests, the highest inter-participant variability was found in blue sensitivity, with $\mathrm{CV}=72 \%$ and the lowest $\mathrm{CV}=58 \%$ in red sensitivity.

The variability of the data indicates that a sample size of 50 patients per treatment group would be sufficient to detect a $22 \%$ to $41 \%$ change in sensitivity for the different functional methods over the trial period, with statistical power of $80 \%$ (Table 4). Likewise, our calculations show that with a sample of $\mathrm{n}=50$ (in each treatment group) we can detect a $3.4 \mathrm{~min}$ difference in rod-cone break.

Due to the length of time it took to recruit patients that fulfilled all the inclusion and exclusion criteria, and being cognizant of the expiry date of the special consignment of drug, we chose to cease recruitment when we achieved a sample size sufficient for a difference to be detected in the functional aspects of the study, allowing for a $5 \%-10 \%$ attrition rate per year. Statistical power and sample size were calculated using the nQuery Advisor 7.0 software (Statistical Solutions, Cork, Ireland) and the StatMate software (Version 2.00, GraphPad Software, San Diego, California, USA).

\section{Statistical analysis}

Analysis will be performed using SPSS for Windows (SPSS Inc., Chicago, IL, USA). The difference in progression rates of AMD and incidence of late AMD will be compared between the two treatment groups. Comparisons of proportions using Chi-square tests will be used for categorical data. Multivariate regression analysis will be used to control for confounders. Although randomization presumes achieving no major differences between two groups in the other than statin intake factors, we will control the analysis for age, as the age would have a significant variation within each group,

Table 4 The level of detectable change (\%) in visual function for three sample sizes and two statistical powers, at a significance level of 0.05 given our measured variability

\begin{tabular}{lllllll}
\hline & \multicolumn{7}{l}{ Number of subjects per group } \\
\cline { 2 - 7 } & $\mathbf{5 0}$ subjects & $\mathbf{4 0}$ subjects & $\mathbf{3 0}$ subjects \\
\hline Statistical power & $\mathbf{8 0 \%}$ & $\mathbf{9 0 \%}$ & $\mathbf{8 0} \%$ & $\mathbf{9 0 \%}$ & $\mathbf{8 0 \%}$ & $\mathbf{9 0 \%}$ \\
Red threshold & 33 & 38 & 38 & 44 & 43 & 50 \\
Blue threshold & 41 & 47 & 47 & 53 & 53 & 61 \\
Flicker threshold & 38 & 44 & 44 & 53 & 49 & 57 \\
Total static & 37 & 43 & 43 & 49 & 49 & 56 \\
DA - RCB & 22 & 25 & 24 & 28 & 28 & 32 \\
\hline
\end{tabular}

Abbreviation: DA - RCB, rod-conebreak in dark adaptation. 
Table 5 References on associations between cholesterol-lowering medications and development of AMD

\begin{tabular}{|c|c|c|}
\hline Reference & Details of study & Conclusion \\
\hline Delcourt et al 200I & $\begin{array}{l}\text { Cross-sectional study } \\
\text { Age } \geq 60 \text { years } \\
\mathrm{N}=2584\end{array}$ & $\begin{array}{l}\text { Late AMD was not significantly associated with current use of } \\
\text { hypocholesterolemic drugs (OR } 0.58,95 \% \mathrm{Cl} 0.22-1.53 \text { ), cardiovascular } \\
\text { disease, known diabetes or blood pressure } \\
\text { Obesity }(\mathrm{BMI}>30 \text { ) was associated with a two fold higher risk of late AMD } \\
\text { (OR } 2.29,95 \% \mathrm{Cl} \text { I-5.23) }\end{array}$ \\
\hline McCarty et al $200 \mathrm{Ia}$ & $\begin{array}{l}\text { Cross-sectional study } \\
\text { Age } \geq 40 \text { years } \\
N=4744\end{array}$ & $\begin{array}{l}\text { Past or present use of a cholesterol-lowering medication associated with } \\
\text { an increased prevalence of early AMD (OR I.72, 95\% CI I.18-2.49) }\end{array}$ \\
\hline McCarty et al $200 \mathrm{Ib}$ & $\begin{array}{l}\text { Population-based cohort study } \\
\text { Age } \geq 40 \text { years } \\
N=4744\end{array}$ & $\begin{array}{l}\text { Participants on lipid-lowering medications were almost } 4 \text { times less } \\
\text { likely to experience AMD progression ( } 3.6 \% \text { vs I } 3 \%) \text {. Findings were not } \\
\text { significant due to the small numbers of subjects in this group }\end{array}$ \\
\hline Hall et al $200 \mathrm{I}$ & $\begin{array}{l}\text { Cross-sectional study } \\
\text { Age } 66-75 \text { years } \\
\mathrm{N}=379\end{array}$ & $\begin{array}{l}\text { AMD was more common amongst those who were not taking statins } \\
(p=0.02) .22 \% \text { of those not taking statins had AMD, whilst } 4 \% \text { on statins } \\
\text { had AMD }\end{array}$ \\
\hline Klein et al 2003a & $\begin{array}{l}\text { Population-based cohort study } \\
\text { Age } 43-86 \text { yrs } \\
N=3684 \text { for } 5 \text { years of follow up } \\
N=2764 \text { for } 10 \text { years of follow up }\end{array}$ & $\begin{array}{l}\text { Higher serum HDL cholesterol at baseline was associated with pure } \\
\text { geographic atrophy (RR }=1.29 \text { per } 10 \mathrm{mg} / \mathrm{dl} \text { increase }(1.05-1.58) . \\
\text { Only } 3.9 \% \text { of the studied population were taking statins at baseline } \\
\text { No significant association between the use of lipid-lowering medication } \\
\text { (including nicotinic acid, fibric acid derivatives, bile acid sequestrants and } \\
\text { statins) with early AMD incidence or progression }\end{array}$ \\
\hline van Leeuwen et al 2003 & $\begin{array}{l}\text { Population-based cohort study } \\
\text { Age } \geq 55 \text { years } \\
\mathrm{N}=4822 \\
452 \text { on lipid-lowering medications } \\
\text { Follow up at } 2 \text { and } 6.5 \text { years }(26,78 \text { I } \\
\text { person years) }\end{array}$ & $\begin{array}{l}\text { No significant association between the use of lipid-lowering medication } \\
\text { (including nicotinic acid, fibric acid derivatives, bile acid sequestrants and } \\
\text { statins) with early AMD incidence or progression (HR I.0, } 95 \% \mathrm{Cl} 0.7-1.5 \text { ) }\end{array}$ \\
\hline McGwin et al 2003 & $\begin{array}{l}\text { Nested case-control study } \\
\text { Age } \geq 50 \text { years } \\
550 \text { cases of AMD and } 5500 \text { matched } \\
\text { controls }\end{array}$ & $\begin{array}{l}\text { Cases of early AMD were } 70 \% \text { less likely to have filled a statin prescription } \\
\text { in comparison to those without early AMD (OR } 0.30,95 \% \mathrm{Cl} 0.2 \mathrm{I}-0.45) \\
\text { Number of filled prescriptions was taken as an indication of statin use, } \\
\text { rather than subject reported use }\end{array}$ \\
\hline Wilson et al 2004 & $\begin{array}{l}\text { Retrospective consecutive case series } \\
\text { Age } \geq 60 \text { years, all subjects had AMD }\end{array}$ & $\begin{array}{l}\text { Statins use was associated with an almost } 50 \% \text { reduction in the risk of } \\
\text { developing CNV (HR } 0.54,95 \% \mathrm{Cl} 0.33-0.87) \\
\text { Triglyceride levels were positively correlated with the rate of CNV } \\
(\mathrm{HR} \quad \mathrm{I} .30,95 \% \mathrm{Cl} \mathrm{I} .02-1.66)\end{array}$ \\
\hline McGwin et al 2005 & $\begin{array}{l}\text { Case-control study based on the } \\
\text { population-based cohort } \\
\text { Age } 45-65 y r s \\
87 \text { I AMD cases, II,7I } 7 \text { controls }\end{array}$ & $\begin{array}{l}\text { Use of cholesterol-lowering medications was inversely associated with AMD } \\
\text { I I \% of those with AMD were using these medications, compared to I } 2.3 \% \\
\text { of controls (OR } 0.89,95 \% \mathrm{Cl} 0.63-0.99 \text { ) }\end{array}$ \\
\hline Smeeth et al 2005 & $\begin{array}{l}\text { Population-based case-control study } \\
\text { Age } \geq 50 \text { years } \\
\text { I8,007 AMD cases and } 86,169 \text { age } \\
\text { and gender matched controls }\end{array}$ & $\begin{array}{l}\text { No significant association between the use of statins and a diagnosis of } \\
\text { AMD (OR } 0.93,95 \% \mathrm{Cl} 0.8 \mathrm{I}-1.07)\end{array}$ \\
\hline McGwin et al 2006 & $\begin{array}{l}\text { Case-control study } \\
\text { Age } \geq 65 \text { years } \\
390 \text { AMD cases , } 2365 \text { controls }\end{array}$ & $\begin{array}{l}\text { Cases of AMD were more likely to be older and white than controls } \\
(\mathrm{p}<0.00 \mathrm{I}) \\
\text { Nearly equal proportions of cases and controls used cholesterol-lowering } \\
\text { medications (OR I.06, } 95 \% \mathrm{Cl} 0.8 \mathrm{I}-\mathrm{I} .40)\end{array}$ \\
\hline Tan et al 2007 & $\begin{array}{l}\text { Population-based cohort study } \\
\text { Age } \geq 50 \text { years } \\
N=3654 \text { at baseline } \\
N=1952 \text { at } 10 \text { years }\end{array}$ & $\begin{array}{l}\text { Those on statins had a reduced risk of developing indistinct soft drusen } \\
\text { at } 10 \text { years }(\mathrm{HR} 0.33 ; 95 \% \mathrm{Cl} 0.13-0.84) \text { and also had a borderline } \\
\text { nonsignificant reduced risk of any AMD }\end{array}$ \\
\hline
\end{tabular}

(Continued) 
Table 5 (Continued)

\begin{tabular}{lll}
\hline Reference & Details of study & Conclusion \\
\hline Klein et al 2007a & $\begin{array}{l}\text { Randomized clinical trial of hormone } \\
\text { replacement therapies }\end{array}$ & $\begin{array}{l}\text { Use of statins was inversely associated with soft drusen (OR 0.8I, 95\% } \\
\text { Cl 0.68-0.96), but not with early or advanced AMD }\end{array}$ \\
& $\begin{array}{l}\text { Age 50-79 years } \\
\mathrm{N}=4288 \text { women }\end{array}$ & \\
Klein et al 2007b & $\begin{array}{l}\text { Population-based cohort study } \\
\text { Age 43-86 years }\end{array}$ & $\begin{array}{l}\text { Statin use was not associated with the five year incidence of: } \\
\text { Early AMD (OR I.16 95\% Cl 0.7I-1.9I) }\end{array}$ \\
& $\mathrm{N}=2962$ at baseline & Late AMD (OR I.27 95\% Cl 0.60-2.69) \\
Friedman et al 2005 & $\mathrm{N}=2204$ at 5 years & Progression of AMD (OR I.16 95\% Cl 0.75-I.78) \\
IOVS 46 (Suppl):199 & Case-control study & Those on statins had a reduced risk of AMD (RR 0.50, 95\% Cl: 0.23-I.09) \\
\hline
\end{tabular}

Abbreviations: AMD, age-related macular degeneration; BMI, body mass index; Cl, confidence interval; HR, hazard ratio; OR, odds ratio; RR, relative risk.

and also for gender, smoking status and other variables, which would retain in the final model if they change the $\beta$ coefficients by more than $5 \%$.

The analysis will be conducted on an 'intention to treat' basis, incorporating the total study population. An 'on protocol' analysis will also be performed. Special attention will be given to the handling of patients who did not return for examination and photography. Adverse events and reasons for withdrawals will be analyzed. For the withdrawals the latest data obtained prior to the withdrawal will be carried forward to the following years, to ensure that the outcome from these participants would not be missed in the analysis. Kaplan-Meier survival analysis with log rank test statistics for equality of survival distributions between the two treatment groups will be applied to the data on reaching the end-point of late AMD.

Psychophysical outcomes will be analyzed using parametric and nonparametric comparisons between the two treatment groups. A receiver operator characteristic will be determined for each test in order to consider test sensitivity and specificity at different criteria, positive and negative predictive values and diagnostic accuracy (Hanley et al 1983; Ariyasu et al 1996). The capacity of each test to discriminate between diseased and control groups will be determined by calculating the either d-prime or a-prime values. The a-prime is a nonparametric index of discriminability.

In the genetic arm of the study, the haplotype risks will be established using logistic regression, with case status of AMD as the binary outcome. The likelihood ratio test will be used to compare dominant, recessive and additive models for the effect of SNP haplotypes with the unconstrained model (allowing separate effects in each haplotype category).

A combined effect of genetic and environmental risks will be explored in multivariate regression analysis, and possible interaction between various risk factors will be investigated using quantitative measures of interaction (Rothman and Greenland 1998).

\section{Recruitment results}

Recruitment started in April 2003 and continued until the end of 2006. A total of 271 people were referred, based upon the ocular pathology. Of these, 152 fulfilled the eligibility criteria for recruitment. Participants were excluded for the following reasons: development of bilateral late AMD $(n=20)$, high cholesterol levels requiring cholesterollowering medications $(n=7)$, already on cholesterol-lowering medications $(\mathrm{n}=18)$, had low vision $(\mathrm{n}=5)$, glaucoma $(n=16)$, significant cataract $(n=12)$, or diabetes, major illness or cancer $(n=22)$, had difficulty understanding the study requirements $(n=6)$, were unable to attend the study centre $(n=8)$; and 5 people deceased prior to recruitment into ARMSS. A further 38 apparently eligible participants chose not to enroll in the study 114 participants were finally enrolled and randomized (Figure 1). The recruitment was difficult due to the stringent eligibility criteria to allow meaningful results from the functional tests and to exclude participants who need treatment with statins.

The average age of the enrolled participants was $74.6 \pm$ 7.0 years, with $77(67.5 \%)$ being female, $6(5.3 \%)$ current and $58(50.9 \%)$ former smokers. Of the total sample, 64 participants had early AMD in both eyes and 50 participants had one eye with early AMD and the other eye had either geographic atrophy or neovascular AMD. To date, mid-2008, for $78 \%$ of the enrolled participants a three-year treatment period is completed. The study continues, with $23 \%$ of the enrolled participants still to be followed up. We anticipate the examinations to be finished by the end of 2009 and results are expected in 2010. 


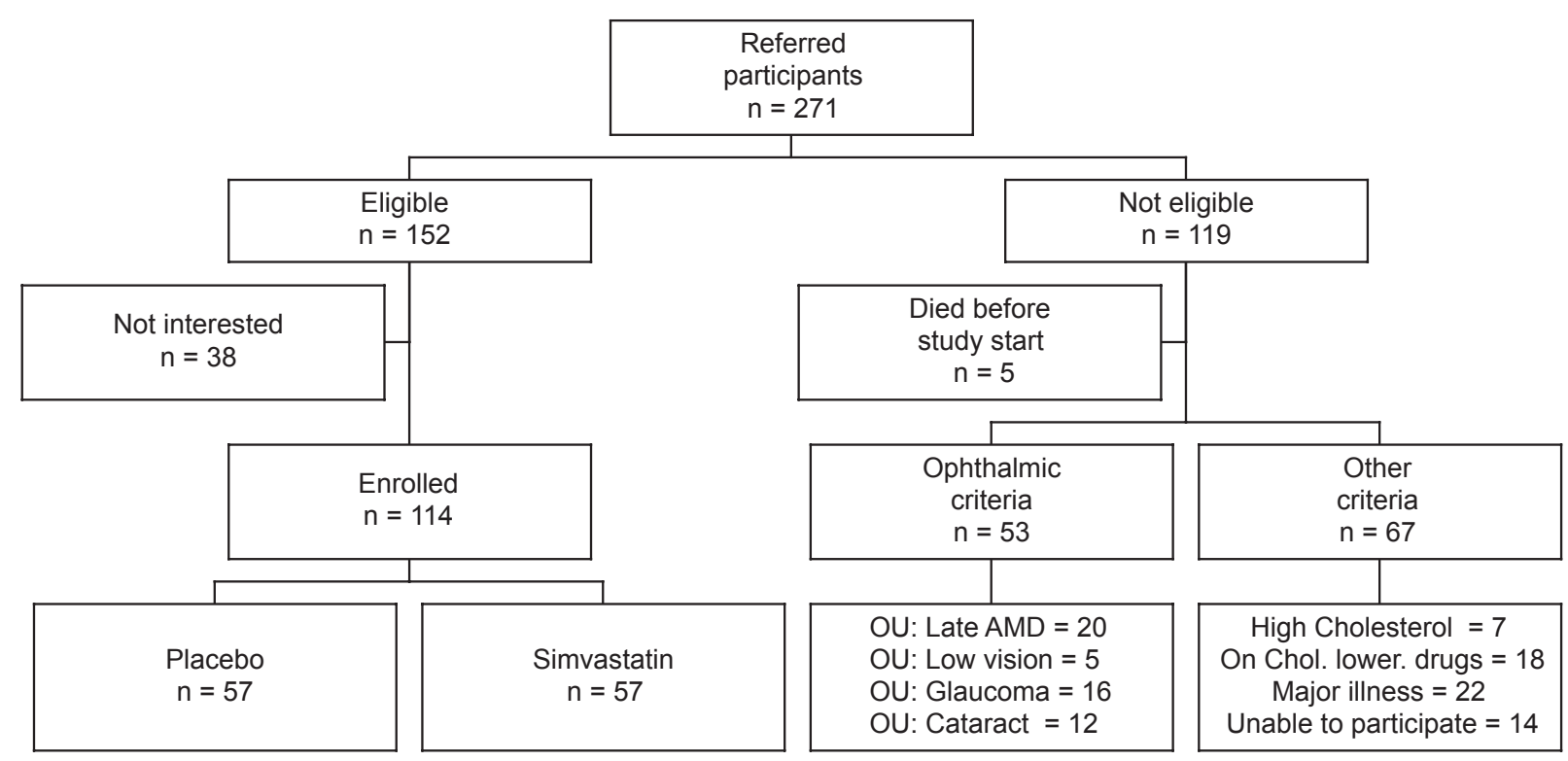

Figure I Flow chart of the recruitment into the Age-Related Maculopathy Statin Study.

\section{Conclusion}

AMD is a debilitating and costly disease for both the individual and the community. We have very little to offer people who are at risk of this disease in terms of prevention and slowing progression. Statins are lipid-lowering, anti-inflammatory agents with pleiotropic actions. Emerging knowledge about AMD genetics and pathology suggests a possible role for statins in prevention and delaying progression of AMD.

However, whilst there is increasing epidemiological evidence to support the notion of using lipid-lowering medications in AMD, not all evidence supports this hypothesis. To date there is no published randomized clinical trial designed to answer this question. This paper outlines how such a trial is being run. The ARMSS trial has finished recruiting. Implemented measures of visual function will add invaluable additional information to that obtained from tradition fundus photographs and grading. If a protective effect is found for the long-term use of statin as a prophylactic, preventative therapy for AMD development, or progression, then this would be a feasible strategy to adopt.

\section{Acknowledgments}

The ARMSS project is a recipient of funds from The Ian Potter Foundation, John Reid Charitable Trust, and Royal Victorian Eye and Ear Hospital and NHMRC grant 350224 (RHG/AJV). RHG is supported by an NHMRC career development fellowship. Merck, Sharp and Dohme (Sydney, Australia) supplied the active simvastatin and placebo medication for the trial.

\section{References}

Alcocer L. 2003. Statins for everybody? New evidence on the efficacy and safety of the inhibitors of HMG Co-A reductase. Am J Ther, 10:423-8.

Alvarez de Sotomayor M, Andriantsitohaina R. 2001. Simvastatin and $\mathrm{Ca}(2+)$ signaling in endothelial cells: involvement of rho protein. Biochem Biophys Res Commun, 280:486-90.

[AREDS] Age-Related Eye Disease Study Research Group. 1999. The AgeRelated Eye Disease Study (AREDS): design implications. AREDS report no. 1. Control Clin Trials, 20:573-600.

[AREDS] Age-Related Eye Disease Study Research Group. 2001. A randomized, placebo-controlled, clinical trial of high-dose supplementation with vitamins $\mathrm{C}$ and $\mathrm{E}$, beta carotene, and zinc for age-related macular degeneration and vision loss: AREDS report no. 8. Arch Ophthalmol, 119:1417-36.

Ariyasu R, Lee P, Linton K, et al. 1996. Sensitivity, specificity, and predictive values of screening tests for eye conditions in a clinic-based population. Ophthalmology, 103:1751-60.

Bailey I, Lovie J. 1976. New design principles for visual acuity letter charts. Am J Optom Physiol Optics, 53:740-5.

Baird P, Richardson A, Robman L, et al. 2006. Apolipoprotein (APOE) gene is associated with progression of age-related macular degeneration (AMD). Hum Mutat, 27:337-42.

Baird PN, Robman, LD, Richardson, AJ, et al. 2008. Gene-environment interaction in progression of AMD - the CFH gene, smoking and exposure to chronic infection. Hum Mol Genet, 17:1299-305.

Baker S, Tarnopolsky M. 2005. Statin-associated neuromyotoxicity. Timely Top Med Cardiovasc Dis, 9:E26.

Bellosta S, Ferri N, Bernini F, et al. 2000. Non-lipid-related effects of statins. Ann Med, 32:164-76.

Bird AC, Bressler NM, Bressler SB, et al. 1995. An international classification and grading system for age-related maculopathy and age-related macular degeneration. The International ARM Epidemiological Study Group. Surv Ophthalmol, 39:367-74.

Brown B, Adams A, Coletta NJ, et al. 1986. Dark adaptation in age-related maculopathy. Ophthalmic Physiol Optics, 6:81-4.

Chuo JY, Wiens M, Etminan M, et al. 2007. Use of lipid-lowering agents for the prevention of age-related macular degeneration: a meta-analysis of observational studies. Ophthalmic Epidemiol, 14:367-74.

Curcio CA, Medeiros NE, Millican CL. 1996. Photoreceptor loss in agerelated macular degeneration. Invest Ophthalmol Vis Sci, 37:1236-49. 
Delcourt C, Michel F, Colvez A, et al. 2001. Associations of cardiovascular disease and its risk factors with age-related macular degeneration: the POLA study. Ophthalmic Epidemiol, 8:237-49.

Demirel S, Vingrys AJ. 1994. Eye movements during perimetry and the effect that fixational instability has on perimetric outcomes. J Glaucoma, 3:28-35.

Dimitrov PN, Guymer RH, Zele AJ, et al. 2008. Measuring rod and cone dynamics in age-related maculopathy. Invest Ophthalmol Vis Sci, 49:55-65.

Edwards AO, Ritter R 3rd, Abel KJ, et al. 2005. Complement factor $\mathrm{H}$ polymorphism and age-related macular degeneration. Science, 308:421-4.

Friedman E, Rigas IK, Makar M. 2005. The relationship of statin use to the development of age-related macular degeneration [abstract]. Invest Ophthalmol Vis Sci ARVO, 46:199.

Friedman E. 2004. Update of the vascular model of AMD. Br J Ophthalmol, 88:161-3.

Gunkel R, Gouras P. 1963. Changes in scotopic visibility threshold with age. Arch Ophthalmol, 69:4-9.

Guymer R, Luthert P, Bird A. 1999. Changes in Bruch's membrane and related structures with age. Prog Ret Eye Res, 18:59-90.

Hageman GS, Anderson DH, Johnson LV, et al. 2005. A common haplotype in the complement regulatory gene factor $\mathrm{H}(\mathrm{HF} 1 / \mathrm{CFH})$ predisposes individuals to age-related macular degeneration. Proc Natl Acad Sci US A, 102:7227-32.

Hageman GS, Luthert PJ, Victor Chong NH, et al. 2001. An integrated hypothesis that considers drusen as biomarkers of immune-mediated processes at the RPE-Bruch's membrane interface in aging and agerelated macular degeneration. Prog Retin Eye Res, 20:705-32.

Haimovici R, Gantz DL, Rumelt S, et al. 2001. The lipid composition of drusen, Bruch's membrane, and sclera by hot stage polarizing light microscopy. Invest Ophthalmol Vis Sci, 42:1592-9.

Haines JL, Hauser MA, Schmidt S, et al. 2005. Complement factor H variant increases the risk of age-related macular degeneration. Science, 308:419-21.

Hall NF, Gale CR, Syddall H, et al. 2001. Risk of macular degeneration in users of statins: cross sectional study. BMJ, 323:375-6.

Hanley JM, Haugen T, Heath E. 1983. Biosynthesis and processing of rat haptoglobin. J Biol Chem, 258:7858-69.

Hassell JB, Weih LM, Keeffe JE. 2000. A measure of handicap for low vision rehabilitation: the impact of vision impairment profile. Clin Exp Ophthalmol, 28:156-61.

Hess D, Fagan S. 2001. Pharmacology and clinical experience with simvastatin. Expert Opin Pharmacother, 2:153-63.

Hunninghake DB, Knopp RH, Schonfeld G, et al. 1990. Efficacy and safety of pravastatin in patients with primary hypercholesterolemia. I. A doseresponse study. Atherosclerosis, 85:81-9.

Inoue I, Goto S, Mizotani K, et al. 2000. Lipophilic HMG-CoA reductase inhibitor has an anti-inflammatory effect: reduction of MRNA levels for interleukin-1beta, interleukin-6, cyclooxygenase-2, and p22phox by regulation of peroxisome proliferator-activated receptor alpha (PPARalpha) in primary endothelial cells. Life Sciences, 67:863-76.

Jialal I, Stein D, Balis D, et al. 2001. Effect of hydroxymethyl glutaryl coenzyme a reductase inhibitor therapy on high sensitive C-reactive protein levels. Circulation, 103:1933-5.

Jones P, Kafonek S, Laurora I, et al. 1998. Comparative dose efficacy study of atorvastatin versus simvastatin, pravastatin, lovastatin, and fluvastatin in patients with hypercholesterolemia (the CURVES study). Am J Cardiol, 81:582-7.

Keeffe J, McCarty C, Hassell J, et al. 1999. Description and measurement of handicap caused by vision impairment. Aust $N Z$ J Ophthalmol, 27:184-6.

Klein R, Deng Y, Klein BE, et al. 2007a. Cardiovascular disease, its risk factors and treatment, and age-related macular degeneration: Women's Health Initiative Sight Exam ancillary study. Am J Ophthalmol, 143:473-83.
Klein R, Klein BE. 2004. Do statins prevent age-related macular degeneration? Am J Ophthalmol, 137:747-9.

Klein R, Klein BE, Tomany SC, et al. 2003a. The association of cardiovascular disease with the long-term incidence of age-related maculopathy: the Beaver Dam Eye Study. Ophthalmology, 110:636-43.

Klein R, Klein BE, Tomany SC, et al. 2003b. Relation of statin use to the 5-year incidence and progression of age-related maculopathy. Arch Ophthalmol, 121:1151-5.

Klein R, Knudtson MD, Klein BE. 2007b. Statin use and the five-year incidence and progression of age-related macular degeneration. Am J Ophthalmol, 144:1-6.

Klein RJ, Zeiss C, Chew EY, et al. 2005. Complement factor H polymorphism in age-related macular degeneration. Science, 308:385-9.

Kuvin JT, Karas RH. 2003. The effects of LDL reduction and HDL augmentation on physiologic and inflammatory markers. Curr Opin Cardiol, 18:295-300.

Kwak B, Mulhaupt F, Veillard N, et al. 2001. The HMG-CoA reductase inhibitor simvastatin inhibits IFN-gamma induced MHC class II expression in human vascular endothelial cells. Swiss Med Wkly, 131:41-6.

Lamb T. 1981. The involvement of rod photoreceptors in dark adaptation. Vision Res, 21:1773-82.

Lamb T, Pugh E, Jr. 2004. Dark adaptation and the retinoid cycle of vision. Prog Ret Eye Res, 23:307-80.

Lamperti C, Naini A, Lucchini V, et al. 2005. Muscle coenzyme Q10 level in statin-related myopathy. Arch Neurol, 62:1709-12.

Ludvigh E, McCarthy E. 1938. Absorption of the visible light by the refractive media of the human eye. Arch Ophthalmol, 20:37.

[MPSG] Macular Photocoagulation Study Group. 1991. Laser photocoagulation of subfoveal neovascular lesions in age-related macular degeneration. Results of a randomized clinical trial. Macular Photocoagulation Study Group. Arch Ophthalmol, 109:1220-31.

McCarty CA, Mukesh BN, Fu CL, et al. 2001a. Risk factors for agerelated maculopathy: the Visual Impairment Project. Arch Ophthalmol, 119:1455-62.

McCarty CA, Mukesh BN, Guymer RH, et al. 2001b. Cholesterol-lowering medications reduce the risk of age-related maculopathy progression. $M J A, 175: 17$.

McGwin G Jr, Modjarrad K, Hall TA, et al. 2006. 3-hydroxy-3methylglutaryl coenzyme a reductase inhibitors and the presence of age-related macular degeneration in the Cardiovascular Health Study. Arch Ophthalmol, 124:33-7.

McGwin G Jr, Owsley C, Curcio CA, et al. 2003. The association between statin use and age related maculopathy. Br J Ophthalmol, $87: 1121-5$

McGwin G Jr, Xie A, Owsley C. 2005. The use of cholesterol-lowering medications and age-related macular degeneration. Ophthalmology, 112:488-94.

Metha AB, Vingrys AJ, Badcock DR. 1993. Calibration of a colour monitor for visual psychophysics. Beh Res Meth Instrum Comp, 25:371-83.

Mitchell P, Smith W, Attebo K, et al. 1995. Prevalence of age-related maculopathy in Australia. Ophthalmology, 102:1450-60.

[NHFA] National Heart Foundation of Australia, Cardiac Society of Australia and New Zealand. 2001. Lipid management guidelines 2001. Med $J$ Aust, 175(Suppl):S57-S85.

Owsley C, Jackson G, White M, et al. 2001. Delays in rod-mediated dark adaptation in early age-related maculopathy. Ophthalmology, 108:1196-202.

Owsley C, Jackson GR, Cideciyan AV, et al. 2000. Psychophysical evidence for rod vulnerability in age-related macular degeneration. Invest Ophthalmol Vis Sci, 41:267-73.

Phipps JA, Guymer RH, Vingrys AJ. 2003. Loss of cone function in agerelated maculopathy. Invest Ophthalmol Vis Sci, 44:2277-83.

Pruefer D, Scalia R, Lefer AM. 1999. Simvastatin inhibits leukocyteendothelial cell interactions and protects against inflammatory processes in normocholesterolemic rats. Arterioscler Thromb Vasc Biol, 19:2894-900. 
Robman L, McNeil J, Dimitrov P, et al. 2004. Methodology of the Cardiovascular Health and Age-Related Maculopathy (CHARM) Study. Ophthalmic Epidemiol, 11:161-79.

Rothman K, Greenland S, 1998. Modern Epidemiology. Philadelphia, PA: Lipcott Williams and Wilkins.

Sackett CS, Schenning S. 2002. The age-related eye disease study: the results of the clinical trial. Insight, 27:5-7.

Said F, Weale R. 1959. The variation with age of the spectral transmissivity of the living human crystalline lens. Gerontologia, 3:213-31.

Smeeth L, Cook C, Chakravarthy U, et al. 2005. A case control study of age related macular degeneration and use of statins. Br J Ophthalmol, 89:1171-5.

Smith W, Assink J, Klein R, et al. 2001. Risk factors for age-related macular degeneration: Pooled findings from three continents. Ophthalmology, 108:697-704.

Spaide RF, Ho-Spaide WC, Browne RW, et al. 1999. Characterization of peroxidized lipids in Bruch's membrane. Retina, 19:141-7.

Sunness JS, Massof RW, Johnson MA, et al. 1989. Diminished foveal sensitivity may predict the development of advanced age-related macular degeneration. Ophthalmology, 96:375-81.

Takemoto M, Liao JK. 2001. Pleiotropic effects of 3-hydroxy3-methylglutaryl coenzyme a reductase inhibitors. Arterioscler Thromb Vasc Biol, 21:1712-9.

Tan JS, Mitchell P, Rochtchina E, et al. 2007. Statins and the long-term risk of incident age-related macular degeneration: the Blue Mountains Eye Study. Am J Ophthalmol, 143:685-7.

Taylor H, West S. 1988. A simple system for the clinical grading of lens opacities. Lens Res, 5:175-81.
Taylor HR. 2002. Fred Hollows lecture. Eye care for the community. Clin Exp Ophthalmol, 30:151-4.

Taylor HR, Tikellis G, Robman LD, et al. 2002. Vitamin E supplementation and macular degeneration: randomised controlled trial. $B M J, 325: 11$.

Tikellis G, Robman LD, Dimitrov P, et al. 2007. Characteristics of progression of early age-related macular degeneration: the Cardiovascular Health and Age-Related Maculopathy Study. Eye, 21:169-76.

van Leeuwen R, Klaver CC, Vingerling JR, et al. 2004a. Cholesterol and age-related macular degeneration: is there a link? Am J Ophthalmol, 137:750-2.

van Leeuwen R, Tomany SC, Wang JJ, et al. 2004b. Is medication use associated with the incidence of early age-related maculopathy? Pooled findings from 3 continents. Ophthalmology, 111:1169-75.

van Leeuwen R, Vingerling JR, Hofman A, et al. 2003. Cholesterol lowering drugs and risk of age related maculopathy: prospective cohort study with cumulative exposure measurement. BMJ, 326:255-6.

VanNewkirk M, Nanjan M, Wang J, et al. 2000. The prevalence of agerelated maculopathy: the Visual Impairment Project. Ophthalmology, 107:1593-600.

Watts G. 2001. Treating patients with low high-density lipoprotein cholesterol: choices, issues and opportunities. Curr Control Trials Cardiovasc Med, 2:118-22.

Wilson HL, Schwartz DM, Bhatt HR, et al. 2004. Statin and aspirin therapy are associated with decreased rates of choroidal neovascularization among patients with age-related macular degeneration. Am J Ophthalmol, 137:615-24.

Zele A, Vingrys A. 2005. Cathode-ray-tube monitor artefacts in neurophysiology. J Neurosci Methods, 141:1-7. 
